\title{
Produção, nutrição e incidência do mal do Panamá em bananeira 'Prata Anã' adubada com potássio
}

\author{
José Tadeu Alves da Silva(1) e Fúlvio Rodriguez Simão(1)
} ${ }^{(1)}$ Empresa de Pesquisa Agropecuária de Minas Gerais, Fazenda Experimental de Montes Claros, Caixa Postal 52, CEP 39400-970 Montes
Claros, MG, Brasil. E-mail: josetadeu@epamig.br, fulvio@epamig.br

Resumo - O objetivo deste trabalho foi estimar a dose de K necessária para obter a máxima eficiência física de produção e o nível crítico foliar para o nutriente, bem como verificar a relação da aplicação de K no solo com o equilíbrio nutricional e a incidência do mal do Panamá (Fusarium oxysporum) na bananeira 'Prata Anã' (AAB). O experimento foi realizado por quatro ciclos de produção, na região semiárida de Minas Gerais, em Latossolo Vermelho eutrófico com $69 \mathrm{mg} \mathrm{dm}^{-3}$ de $\mathrm{K}$ disponível. Os tratamentos foram distribuídos em blocos ao acaso, em arranjo fatorial $4 \times 4$, com quatro doses de $\mathrm{K}\left(0,250,500\right.$ e $1.000 \mathrm{~kg} \mathrm{ha}^{-1}$ por ano de $\left.\mathrm{K}_{2} \mathrm{O}\right)$, quatro ciclos de produção e seis repetições. A aplicação de $\mathrm{K}$ no solo não influenciou a produção da bananeira no primeiro ciclo. A dose média de $\mathrm{K}_{2} \mathrm{O}$ para alcançar a máxima eficiência física de produção da 'Prata Anã' no segundo, no terceiro e no quarto ciclos foi de $880 \mathrm{~kg} \mathrm{ha}^{-1}$. Os valores médios dos teores foliares de $\mathrm{N}, \mathrm{K}, \mathrm{Ca}$ e $\mathrm{Mg}$ foram semelhantes entre os ciclos de produção. O nível crítico médio de $\mathrm{K}$ foliar, estimado nos três ciclos de produção, foi de $28,9 \mathrm{~g} \mathrm{~kg}^{-1}$. A adubação potássica aumenta a produção e a tolerância da bananeira 'Prata Anã' ao mal do Panamá, em solo com médio teor de K.

Termos para indexação: Fusarium oxysporum, Musa, avaliação do estado nutricional, recomendação de adubação, resistência induzida pela nutrição.

\section{Yield, nutrition and incidence of Panama disease in 'Prata Anã' banana fertilized with potassium}

\begin{abstract}
The objective of this work was to estimate the K dose necessary to obtain the maximum physical efficiency of production and the critical foliar level of the nutrient, as well as to verify the relationship of soil application of $\mathrm{K}$ with the nutritional balance and the incidence of Panama disease (Fusarium oxysporum) in 'Prata Anã' (AAB) banana. The experiment was conducted during four production cycles in the semiarid region of the state of Minas Gerais, Brazil, in a clayey Oxisol, with $69 \mathrm{mg} \mathrm{dm}^{-3}$ available K. Treatments were distributed in a randomized complete block design in a $4 \times 4$ factorial arrangement, with four $\mathrm{K}$ rates $(0,250$, 500 , and $1,000 \mathrm{~kg} \mathrm{ha}^{-1} \mathrm{~K}_{2} \mathrm{O}$ per year), four production cycles and six replicates. Soil application of $\mathrm{K}$ did not influence banana production in the first cycle. The mean rate of $\mathrm{K}_{2} \mathrm{O}$ to achieve maximum physical efficiency of production of 'Prata Anã' in the second, third, and fourth cycles was $880 \mathrm{~kg} \mathrm{ha}^{-1}$. The mean values of leaf concentrations of $\mathrm{N}, \mathrm{K}, \mathrm{Ca}$, and $\mathrm{Mg}$ were similar between the production cycles. The mean critical foliar level of $\mathrm{K}$, estimated in the three production cycles, was $28.9 \mathrm{~g} \mathrm{~kg}^{-1}$. Fertilization with $\mathrm{K}$ increases the production and the tolerance of 'Prata Anã' banana to the Panama disease, in soil with average content of K.
\end{abstract}

Index terms: Fusarium oxysporum, Musa, evaluation of nutritional status, fertilizer recommendation, nutrition-induced resistance.

\section{Introdução}

Para a adubação potássica da bananeira 'Prata Anã', no Norte de Minas Gerais, recomendam-se doses entre 50 e $750 \mathrm{~kg} \mathrm{ha}^{-1}$ por ano de $\mathrm{K}_{2} \mathrm{O}$ (Silva \& Borges, 2008), de acordo com o teor do nutriente no solo e com a produtividade esperada. No entanto, diversos trabalhos têm estimado doses de $\mathrm{K}$ bem mais elevadas, para obtenção de altas produtividades da bananeira, mesmo em solos com elevada disponibilidade inicial de K.

Silva et al. (2003) obtiveram máxima produtividade, no quarto ciclo da bananeira 'Prata Anã', com a aplicação de $963 \mathrm{~kg} \mathrm{ha}^{-1}$ de $\mathrm{K}_{2} \mathrm{O}$, mesmo em solo com alto teor disponível do nutriente $\left(210 \mathrm{mg} \mathrm{dm}^{-3}\right)$. Os autores relataram que essa dose foi economicamente viável e proporcionou aumento de $11 \%$ na produtividade da bananeira, em comparação à testemunha. Sousa 
et al. (2004) observaram que a produção máxima da bananeira 'Grand Naine', no segundo ciclo, foi obtida com a aplicação de $933 \mathrm{~kg} \mathrm{ha}^{-1}$ de $\mathrm{K}_{2} \mathrm{O}$. Já Silva et al. (2013), ao avaliar a resposta da bananeira 'Prata Anã' irrigada a doses de $\mathrm{K}$ aplicadas no solo, verificaram resposta linear da massa do cacho, do número de frutos por cacho, do número de pencas por cacho e da massa do fruto, no primeiro ciclo de produção, mas apenas do número de frutos por penca, no segundo ciclo, em solo com elevado teor de $\mathrm{K}$ disponível (128 $\mathrm{mg} \mathrm{dm}^{-3}$ ).

Pinto et al. (2005), contudo, não constataram efeitos significativos da aplicação de K sobre a produção do primeiro ciclo da bananeira 'Pacovan' (AAB), cultivada em solo arenoso com $82 \mathrm{mg} \mathrm{dm}^{-3}$ de $\mathrm{K}$ disponível. Já Silva \& Rodrigues (2013) observaram que a máxima eficiência física (31 $\mathrm{Mg} \mathrm{ha}^{-1}$ ) da bananeira 'Prata Anã', no quarto ciclo, foi obtida com a aplicação de $969 \mathrm{~kg}$ ha $^{-1}$ de $\mathrm{K}_{2} \mathrm{O}$ e que o solo apresentava desequilíbrio nutricional, com baixo teor de $\mathrm{Ca}$ e $\mathrm{K}$ e elevado teor de $\mathrm{Mg}$. O desbalanço na disponibilidade de nutrientes diminui a produtividade e a tolerância das plantas a doenças (Alvarez et al., 1981). Martin-Prével (1985) preconiza que, para alcançar alta produtividade da bananeira, os valores de $\mathrm{Ca}: \mathrm{K}: \mathrm{Mg}$ no solo devem corresponder a 60-70, 10 e $20-30 \%$ da saturação por bases, respectivamente.

A disponibilidade de nutrientes no solo tem forte influência sobre a incidência do mal do Panamá em bananeira. Lopes et al. (2008) relataram que áreas de solos com maiores valores de saturação por bases e de Ca disponível apresentaram menores percentuais de bananeira 'Pacovan' com sintomas do mal do Panamá, enquanto Furtado et al. (2009) verificaram menor teor de $\mathrm{N}, \mathrm{K}$ e $\mathrm{S}$ nas folhas da bananeira 'Nanicão' com sintomas do mal do Panamá, em comparação a plantas sadias. Já Silva \& Rodrigues (2013) observaram que a incidência dessa doença na bananeira 'Prata Anã' diminuiu com o aumento das doses de $\mathrm{K}$ aplicadas no solo. Conforme estes autores, a relação desequilibrada entre Ca: K: Mg (49, 6 e 45\% da saturação por bases) provavelmente favoreceu a incidência do mal do Panamá e sua diminuição com a fertilização potássica.

Apesar da relação entre a incidência do mal do Panamá e a nutrição mineral da bananeira já ter sido abordada em pesquisas, ainda são necessários estudos consistentes, que avaliem essa relação por mais tempo e em novos solos.
O objetivo deste trabalho foi estimar a dose de $\mathrm{K}$ necessária para obter a máxima eficiência física de produção e o nível crítico foliar para o nutriente, bem como verificar a relação da aplicação de $\mathrm{K}$ no solo com o equilíbrio nutricional e a incidência do mal do Panamá (Fusarium oxysporum) na bananeira 'Prata Anã' (AAB).

\section{Material e Métodos}

O experimento foi instalado em Latossolo Vermelho eutrófico, argiloso, na Fazenda Experimental da Empresa de Pesquisa Agropecuária de Minas Gerais, localizada em Jaíba, na região semiárida de Minas Gerais ( $15^{\circ} 48^{\prime} 09^{\prime \prime} \mathrm{S}, 43^{\circ} 18^{\prime} 32^{\prime \prime} \mathrm{W}$, a 533 m de altitude). O clima da região é do tipo Aw, segundo a classificação de Köppen. A média anual de precipitação é de $900 \mathrm{~mm}$, a temperatura média de $25^{\circ} \mathrm{C}$ e a umidade relativa do ar é de $56 \%$. O experimento foi realizado de maio de 2009 a novembro de 2013.

Antes da implantação do experimento, foram coletadas amostras de solo na camada $0-0,20 \mathrm{~m}$ de profundidade, para caracterização química e granulométrica, a qual indicou: $\mathrm{pH}$ em $\mathrm{H}_{2} \mathrm{O}$ de 6,3; 2,6 dag $\mathrm{kg}^{-1}$ de matéria orgânica; $4,6 \mathrm{mg} \mathrm{dm}^{-3} \mathrm{de}$ P-Mehlich 1; 0,18 $\mathrm{cmol}_{\mathrm{c}} \mathrm{dm}^{-3}$ de K+ $; 0,0 \mathrm{cmol}_{\mathrm{c}} \mathrm{dm}^{-3} \mathrm{de}$

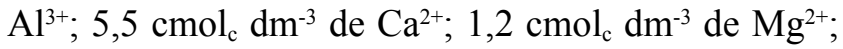
$2,2 \mathrm{cmol}_{\mathrm{c}} \mathrm{dm}^{-3}$ de $\mathrm{H}+\mathrm{Al}$; $\mathrm{V}$ de $76 \%$; relação $\mathrm{Ca}: \mathrm{K}$ : Mg de 80: 3: 17\% da saturação por bases; e 460, 290 e $250 \mathrm{~g} \mathrm{~kg}^{-1}$ de argila, silte e areia, respectivamente.

Foram utilizadas mudas da bananeira 'Prata Anã' (AAB), obtidas de cultura de tecido. O plantio foi realizado em covas de $0,10 \times 0,10 \mathrm{~m}$, abertas nos sulcos de plantio com profundidade de $0,15 \mathrm{~m}$, com espaçamento de 3,0 $\mathrm{m}$ entre linhas. $\mathrm{O}$ espaçamento entre plantas na linha de plantio foi de $2,7 \mathrm{~m}$, o que totalizou 1.235 mudas por hectare. Cada parcela experimental foi constituída por 20 famílias, com seis famílias na parcela útil. Os tratamentos foram distribuídos em delineamento de blocos ao acaso, em arranjo fatorial $4 \times 4$, com quatro doses de $\mathrm{K}_{2} \mathrm{O}(0,250$, 500 e $1.000 \mathrm{~kg} \mathrm{ha}^{-1}$ por ano), quatro ciclos de produção e seis repetições.

A adubação com $\mathrm{K}_{2} \mathrm{O}$ foi iniciada no terceiro mês após o plantio das mudas, com $\mathrm{KCl}\left(58 \%\right.$ de $\left.\mathrm{K}_{2} \mathrm{O}\right)$. As adubações complementares consistiram da aplicação de: $450 \mathrm{~g}$ de superfosfato simples $\left(18 \%\right.$ de $\left.\mathrm{P}_{2} \mathrm{O}_{5}\right)$ por cova, no plantio, e 200 g a cada ciclo de produção; 
$20 \mathrm{~g}$ de ureia ( $44 \%$ de $\mathrm{N}$ ) por família, a cada mês; $50 \mathrm{~g}$ de sulfato de magnésio ( $9 \%$ de $\mathrm{Mg}$ ) a cada 3 meses; e $30 \mathrm{~g}$ de sulfato de zinco ( $20 \%$ de $\mathrm{Zn})$ e $10 \mathrm{~g}$ de ácido bórico (17\% de B) a cada 4 meses. Os adubos foram aplicados manualmente, em semicírculo, a $0,40 \mathrm{~m}$ de distância das plantas. Não houve necessidade da aplicação de calcário, porque a saturação por bases do solo estava em $76 \%$, acima da recomendada por Silva et al. (2008a).

A condução e o manejo do bananal foram realizados com famílias constituídas por plantas mãe, filha e neta. $\mathrm{O}$ experimento foi irrigado por microaspersão, e o manejo da irrigação foi feito com tanque classe A (Costa et al., 2008).

No início da emissão dos cachos, a terceira folha a partir do ápice foi coletada de cada planta útil das parcelas, para análise, tendo-se retirado $0,10 \mathrm{~m}$ do centro do limbo e eliminado a nervura central. $\mathrm{O}$ material colhido foi colocado para secar em estufa com circulação forçada de ar, a $70^{\circ} \mathrm{C}$, por 72 horas. Após a secagem, o material foi moído e analisado quanto aos teores de $\mathrm{N}$, K, Ca e Mg (Malavolta et al., 1997).

Os cachos de cada parcela útil foram colhidos no ponto de colheita, tendo-se avaliado a massa dos cachos e o comprimento do fruto mediano da mão externa da segunda penca de cada cacho.

A incidência de plantas com mal do Panamá (Fusarium oxysporum f. sp. cubense) foi quantificada por meio da identificação dos sintomas visuais da doença: amarelecimento progressivo das folhas mais velhas para as mais novas, com início nos bordos do limbo foliar e evolução no sentido da nervura principal, o que culmina na murcha das folhas. As folhas murchas secam e quebram-se junto ao pseudocaule, o que lhes dá a aparência de "guarda-chuva fechado". Além disso, ocorre ruptura das bainhas, o pseudocaule racha próximo ao solo, e os vasos apresentam coloração pardo-avermelhada (Dias, 2008).

Após a colheita do cacho no quarto ciclo, o solo foi novamente amostrado, na profundidade de $0-0,20 \mathrm{~m}$, em cada parcela, ao lado dos perfilhos, e analisado quimicamente quanto aos teores de $\mathrm{K}, \mathrm{Ca}$ e $\mathrm{Mg}$.

Os resultados foram submetidos à análise de variância, e as médias dos ciclos de produção foram comparadas pelo teste de Tukey, a 5\% de probabilidade. Já as respostas produtivas e dos teores foliares foram ajustadas às doses por meio de regressões.
A máxima eficiência física (MEF) das características avaliadas foi calculada de acordo com Silva \& Rodrigues (2013), tendo-se igualado a zero a derivada primeira da característica avaliada, em função das doses.

\section{Resultados e Discussão}

No primeiro ciclo de produção, a massa do cacho e o comprimento do fruto não foram influenciados pelas doses de K. Silva et al. (2011) obtiveram baixa produtividade da bananeira 'Prata Anã' no primeiro ciclo, em relação aos subsequentes, em Latossolo Vermelho-Amarelo com $58 \mathrm{mg} \mathrm{dm}^{-3}$ de K. Dessa forma, é baixa a probabilidade de resposta da bananeira à aplicação de $\mathrm{K}$ no primeiro ciclo, quando cultivada em solos com teores de $\mathrm{K}$ disponível em torno de $60 \mathrm{mg} \mathrm{dm}^{-3}$, como os observados no presente trabalho. Santos et al. (2009) verificaram resposta da bananeira 'Prata Anã' à aplicação de K, na forma de $\mathrm{KCl}$, em solo com baixo teor do nutriente $\left(31 \mathrm{mg} \mathrm{dm}^{-3}\right)$, no segundo ciclo de produção. Conforme estes autores, a aplicação de até $470 \mathrm{~kg} \mathrm{ha}^{-1}$ de $\mathrm{K}_{2} \mathrm{O}$ não foi suficiente para a inflexão da curva de resposta.

No segundo, no terceiro e no quarto ciclos de produção, a massa do cacho aumentou de forma quadrática em relação às doses de $\mathrm{K}_{2} \mathrm{O}$ (Figura 1). As máximas eficiências físicas para o caráter $(20,1$, 25,3 e $25,3 \mathrm{~kg}$ por cacho de banana, respectivamente) foram obtidas com as aplicações de 875, 890 e $875 \mathrm{~kg} \mathrm{ha}^{-1}$ de $\mathrm{K}_{2} \mathrm{O}$, respectivamente. Essas doses foram próximas às obtidas por Silva et al. (2011), no segundo e no terceiro ciclos da 'Prata Anã' (827 e $835 \mathrm{~kg} \mathrm{ha}^{-1}$, respectivamente), e por Silva \& Rodrigues (2013) no quarto ciclo (963 kg ha-1). Esses dois trabalhos foram realizados em Latossolo Vermelho-Amarelo, com baixos teores de $\mathrm{Ca}$ e $\mathrm{K}$ e elevado teor de $\mathrm{Mg}$ (49: 6: 45\% da saturação por bases, respectivamente). Martin-Prével (1985) afirma que, para que a bananeira alcance elevada produtividade, os valores de $\mathrm{Ca}$ : $\mathrm{K}$ : $\mathrm{Mg}$ no solo devem ocupar 60-70, 10 e $20-30 \%$ da saturação por bases. No presente trabalho, a relação Ca: K: Mg no solo foi de 80: 3: 17\% da saturação por bases, respectivamente, o que indica desequilíbrio ainda maior entre a disponibilidade desses nutrientes no solo, o que favorece a possibilidade de resposta da bananeira à adubação com $\mathrm{K}$. 
As doses de $\mathrm{K}_{2} \mathrm{O}$ aplicadas não influenciaram os teores de $\mathrm{Ca}$ e $\mathrm{Mg}$ disponíveis no solo, após o quarto ciclo de produção; entretanto, elevaram linearmente os de $\mathrm{K}$ disponível $\left(\hat{\mathrm{y}}=0,11+0,0003 \mathrm{x}, \mathrm{R}^{2}=0,999\right)$. Se a dose de $\mathrm{K}_{2} \mathrm{O}$ relativa à máxima eficiência física for utilizada nessa equação, obter-se-á o teor de $\mathrm{K}$ disponível no solo $\left(0,4 \mathrm{cmol}_{\mathrm{c}} \mathrm{dm}^{-3}\right)$ necessário para determinar a MEF no quarto ciclo da bananeira.

No tratamento sem aplicação de K, os teores de $\mathrm{Ca}, \mathrm{K}$ e $\mathrm{Mg}$ disponíveis no solo após o quarto ciclo foram de 8,4, $0,1 \mathrm{e} 1,1 \mathrm{cmol}_{\mathrm{c}} \mathrm{dm}^{-3}$, respectivamente, que equivalem a $88: 1: 11 \%$ da saturação por bases. Com a aplicação de $875 \mathrm{~kg} \mathrm{ha}^{-1}$ de $\mathrm{K}_{2} \mathrm{O}$, esses teores foram de 8,4,0,4 e 1,1 $\mathrm{cmol}_{\mathrm{c}} \mathrm{dm}^{-3}$, que equivalem a $85: 4: 11 \%$ da saturação por bases. O principal motivo para a ocorrência de elevados teores de $\mathrm{Ca}$ no solo foi a alta concentração do elemento na água de irrigação, que apresentou teores de $\mathrm{Ca}, \mathrm{Mg}$ e $\mathrm{CO}_{3}+\mathrm{HCO}_{3}$ de 7,5, 2,0 e 7,0 $\mathrm{mmol}_{\mathrm{c}} \mathrm{L}^{-1}$, respectivamente. Silva et al. (2008a) observaram que os teores de $\mathrm{K}, \mathrm{Ca}$ e $\mathrm{Mg}$ no
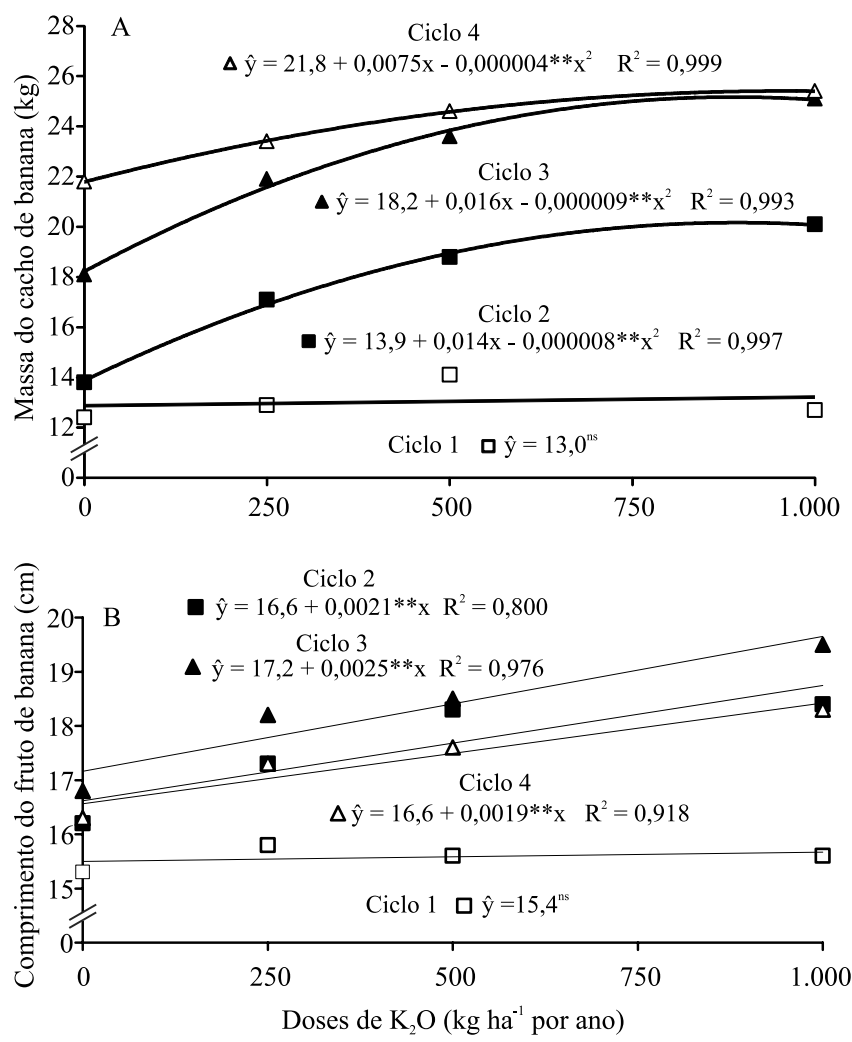

Figura 1. Massa do cacho (A) e comprimento do fruto (B) da bananeira 'Prata Anã', em função da fertilização com $\mathrm{K}_{2} \mathrm{O}$ em quatro ciclos de produção. solo, necessários para obtenção da máxima produção de matéria seca da parte aérea de mudas da bananeira 'Prata Anã', foram de 0,3, 2,0 e 0,9 $\mathrm{cmol}_{\mathrm{c}} \mathrm{dm}^{-3}$, respectivamente.

O comprimento do fruto no segundo, no terceiro e no quarto ciclos apresentou resposta linear às doses de $\mathrm{K}_{2} \mathrm{O}$ aplicadas no solo (Figura 1). As máximas eficiências físicas para a característica, no segundo, no terceiro e no quarto ciclos, foram, respectivamente, de 18,4, 19,4 e 18,3 cm. Esses frutos são classificados na classe 18, que apresenta frutos de 'Prata Anã' com comprimentos entre 18 e $22 \mathrm{~cm}$ (Banana, 2006). Quanto maior o comprimento do fruto, maior o preço de comercialização, o que é uma vantagem adicional da fertilização com K. O comprimento máximo do fruto obtido por Silva et al. (2011), no segundo e no terceiro ciclos da 'Prata Anã', foi de 17,4 e 18,3 cm, respectivamente.

Independentemente da aplicação de $\mathrm{K}$ no solo, a massa do cacho de banana foi menor no primeiro ciclo e maior no terceiro e no quarto ciclos de produção (Tabela 1). Silva \& Rodrigues (2013) mencionam que o tamanho do cacho de banana aumenta com o avanço nos ciclos, até estabilização entre o terceiro e o quarto ciclos.

Os teores foliares médios de $\mathrm{N}, \mathrm{K}, \mathrm{Ca}$ e $\mathrm{Mg}$ foram semelhantes entre os ciclos de produção (Tabela 1). Silva et al. (2002) estabeleceram as seguintes faixas de suficiência nutricional para a bananeira 'Prata Anã': 25$29 \mathrm{~g} \mathrm{~kg}^{-1}$ de N; 27-35 $\mathrm{g} \mathrm{kg}^{-1}$ de K; 4,5-7,5 $\mathrm{g} \mathrm{kg}^{-1} \mathrm{de} \mathrm{Ca}$; e 2,4-4,0 $\mathrm{g} \mathrm{kg}^{-1} \mathrm{de} \mathrm{Mg}$. De acordo com essas faixas, os teores foliares de $\mathrm{Ca}$ e $\mathrm{Mg}$, nos quatro ciclos, estiveram

Tabela 1. Massa do cacho e percentagem de plantas da bananeira 'Prata Anã' com sintomas do mal do Panamá (Fusarium oxysporum f. sp. cubense), bem como teores médios de $\mathrm{N}, \mathrm{K}, \mathrm{Ca}$ e $\mathrm{Mg}$ nas folhas, em quatro ciclos de produção $^{(1)}$.

\begin{tabular}{lcccccc}
\hline Ciclo & $\begin{array}{c}\text { Massa do } \\
\text { cacho } \\
(\mathrm{kg})\end{array}$ & $\begin{array}{c}\text { Plantas } \\
\text { sintomáticas } \\
(\%)\end{array}$ & $\mathrm{N}$ & $\mathrm{K}$ & $\mathrm{Ca}$ & $\mathrm{Mg}$ \\
\hline Primeiro & $13,0 \mathrm{~d}$ & $0 \mathrm{c}$ & $29,7 \mathrm{a}$ & $25,1 \mathrm{a}$ & $11,3 \mathrm{a}$ & $5,7 \mathrm{a}$ \\
Segundo & $17,4 \mathrm{c}$ & $4,0 \mathrm{~b}$ & $30,1 \mathrm{a}$ & $23,4 \mathrm{a}$ & $12,9 \mathrm{a}$ & $5,9 \mathrm{a}$ \\
Terceiro & $22,6 \mathrm{~b}$ & $24,3 \mathrm{a}$ & $29,9 \mathrm{a}$ & $23,7 \mathrm{a}$ & $11,1 \mathrm{a}$ & $5,5 \mathrm{a}$ \\
Quarto & $23,8 \mathrm{a}$ & $24,5 \mathrm{a}$ & $29,3 \mathrm{a}$ & $23,2 \mathrm{a}$ & $11,9 \mathrm{a}$ & $5,4 \mathrm{a}$ \\
\hline Média & 19,2 & 13,2 & 29,8 & 23,9 & 11,8 & 5,6 \\
\hline CV (\%) & 22,3 & 36,4 & 14,2 & 16,4 & 12,6 & 11,2 \\
\hline
\end{tabular}

${ }^{(1)}$ Médias seguidas de letras iguais não diferem pelo teste de Tukey, a $5 \%$ de probabilidade. 
acima dos preconizados como adequados, enquanto os de $\mathrm{K}$ estiveram abaixo (Tabela 1). Esse resultado está de acordo com os da análise do solo e é indicativo de desequilíbrio nutricional, o que favorece resposta da bananeira a aplicações de K no solo. Silva et al. (2011) verificaram relação bem definida entre o teor de $\mathrm{K}$ na folha e a produção da 'Prata Anã'. Os teores foliares de $\mathrm{N}$, nos quatro ciclos, estiveram próximos ao limite superior da faixa de suficiência.

As doses de $\mathrm{K}$ aplicadas no solo elevaram linearmente o teor foliar de $\mathrm{K}$ e reduziram, também de forma linear, os de $\mathrm{N}, \mathrm{Ca}$ e $\mathrm{Mg}$, nos quatro ciclos de produção (Tabela 2). Relações antagonísticas entre $\mathrm{K}, \mathrm{Ca}$ e $\mathrm{Mg}$ são bastante estudadas na nutrição da bananeira. Silva \& Carvalho (2005) constataram que os excessos de $\mathrm{Ca}, \mathrm{Mg}$ e $\mathrm{Mn}$, detectados com o método DRIS, contribuíram para a deficiência de K em 23\% dos bananais de 'Prata Anã' no Norte de Minas Gerais, embora o K tenha sido aplicado periodicamente nessas lavouras. Os autores ainda relataram correlações negativas entre os teores foliares de $\mathrm{K}$ e os de $\mathrm{Ca}, \mathrm{Mg}$ e Mn.

Os níveis críticos foliares de $\mathrm{K}$, para o segundo, o terceiro e o quarto ciclos, foram de 28,5, 29,7 e $28,6 \mathrm{~g} \mathrm{~kg}^{-1}$, respectivamente, obtidos pelas equações (Tabela 2) com uso das doses relativas às máximas eficiências produtivas da bananeira. O nível crítico estimado por Silva et al. (2011), para o segundo e o terceiro ciclos de produção, foi de $28,5 \mathrm{~g} \mathrm{~kg}^{-1}$; já o calculado por Silva \& Rodrigues (2013), para o quarto ciclo, foi de $29,5 \mathrm{~g} \mathrm{~kg}^{-1}$. Apesar de o solo utilizado no presente trabalho ter apresentado maior desequilíbrio entre os teores disponíveis de $\mathrm{Ca}, \mathrm{K}$ e $\mathrm{Mg}$, em relação ao solo dos trabalhos de Silva et al. (2011) e Silva \& Rodrigues (2013), os valores médios do nível crítico de $\mathrm{K}$ na folha mostraram grande estabilidade.

O desbalanço nutricional, além de refletir negativamente na produção da bananeira, aumenta a susceptibilidade da espécie a doenças, como o mal do Panamá (Silva \& Rodrigues, 2013). Solos com disponibilidade de nutrientes desbalanceada são considerados condutivos à doença e favorecem a sua manifestação em poucos anos de cultivo da bananeira. Bananais implantados em solos não condutivos, ou até mesmo supressivos à doença, levam de 10 a 15 anos para apresentar problemas (Ventura \& Hinz, 2002).

No primeiro ciclo, não foi verificada incidência do mal do Panamá, que, no entanto, manifestou-se no segundo, no terceiro e no quarto ciclos de cultivo (Figura 2). A percentagem de plantas com sintomas da doença aumentou seis vezes, do segundo para o quarto ciclo, indício de que o solo onde foi realizado o experimento pode, de fato, ser considerado condutivo, tendo atingido significativo número de plantas doentes em curto espaço de tempo. $\mathrm{O}$ desbalanço nutricional na disponibilidade de nutrientes no solo refletiu-se no estado nutricional das plantas e, muito provavelmente, foi o responsável pela condutividade à doença. Furtado et al. (2009) relataram sintomas do mal do Panamá na bananeira 'Nanicão"' desbalanceada nutricionalmente, e detectaram menores teores de N, K e S nas folhas das plantas doentes, em comparação às sadias.

A percentagem de plantas com sintomas da doença, no segundo, no terceiro e no quarto ciclos, diminuiu linearmente com as doses de $\mathrm{K}_{2} \mathrm{O}$ aplicadas no solo (Figura 2). Portanto, a redução no desbalanço na disponibilidade de $\mathrm{K}, \mathrm{Ca}$ e $\mathrm{Mg}$ no solo causada pela fertilização potássica tornou o solo mais supressivo à doença. Esses resultados são semelhantes aos observados por Silva \& Rodrigues (2013), em Latossolo Vermelho-Amarelo deficiente em $\mathrm{K}$ e $\mathrm{Ca}$, mas com excesso de $\mathrm{Mg}$, no quarto ciclo de produção da 'Prata Anã', no Norte de Minas Gerais. Segundo Zambolim \& Ventura (1993), o efeito da nutrição é marcante na redução da incidência de doenças em plantas com algum grau de tolerância ou moderada

Tabela 2. Regressões entre os teores $\left(\mathrm{g} \mathrm{kg}^{-1}\right)$ de $\mathrm{N}, \mathrm{K}, \mathrm{Ca}$ e $\mathrm{Mg}$ na folha da bananeira 'Prata Anã', em função de doses de $\mathrm{K}_{2} \mathrm{O}$ aplicadas no solo, em quatro ciclos de produção.

\begin{tabular}{|c|c|c|c|c|}
\hline Ciclo & $\mathrm{N}$ & $\mathrm{K}$ & $\mathrm{Ca}$ & $\mathrm{Mg}$ \\
\hline Primeiro & $\hat{\mathrm{y}}=28,6-0,0022 * \mathrm{x}\left(\mathrm{R}^{2}=0,91\right)$ & $\hat{y}=17,6+0,017 * * x\left(R^{2}=0,99\right)$ & $\hat{\mathrm{y}}=11,6-0,001 * \mathrm{x}\left(\mathrm{R}^{2}=0,90\right)$ & $\hat{\mathrm{y}}=6,6-0,002 * * x\left(\mathrm{R}^{2}=0,99\right)$ \\
\hline Segundo & $\hat{\mathrm{y}}=31,0-0,0021 * \mathrm{x}\left(\mathrm{R}^{2}=0,71\right)$ & $\hat{y}=16,2+0,014 * * x\left(R^{2}=0,95\right)$ & $\hat{\mathrm{y}}=15,0-0,002 * * x\left(\mathrm{R}^{2}=0,89\right)$ & $\hat{\mathrm{y}}=6,6-0,001 * \mathrm{x}\left(\mathrm{R}^{2}=0,81\right)$ \\
\hline Terceiro & $\hat{\mathrm{y}}=31,3-0,003^{*} \mathrm{x}\left(\mathrm{R}^{2}=0,94\right)$ & $\hat{y}=18,1+0,013 * * x\left(R^{2}=0,94\right)$ & $\hat{y}=13,7-0,006^{* *} x\left(R^{2}=0,99\right)$ & $\hat{y}=5,3-0,0017 * * x\left(R^{2}=0,96\right)$ \\
\hline Quarto & $\hat{y}=30,5-0,0011 * x\left(R^{2}=0,93\right)$ & $\hat{\mathrm{y}}=19,0+0,011 * * \mathrm{x}\left(\mathrm{R}^{2}=0,96\right)$ & $\hat{\mathrm{y}}=13,3-0,003 * \mathrm{x}\left(\mathrm{R}^{2}=0,90\right)$ & $\hat{\mathrm{y}}=4,7-0,001 * \mathrm{x}\left(\mathrm{R}^{2}=0,91\right)$ \\
\hline
\end{tabular}

* e **Significativo a 5 e $1 \%$ de probabilidade, respectivamente. 


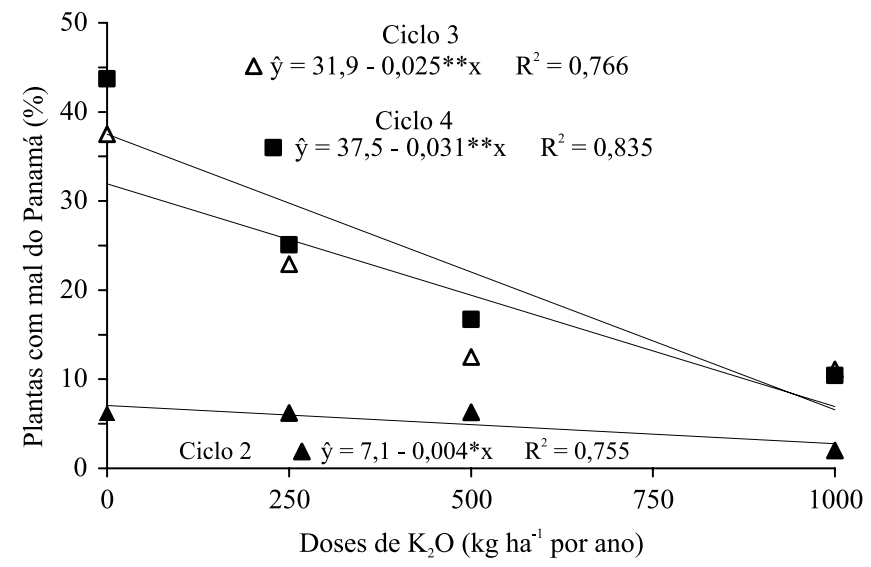

Figura 2. Incidência de plantas da bananeira 'Prata Anã' com mal do Panamá (Fusarium oxysporum f. sp. cubense), em função da fertilização com $\mathrm{K}_{2} \mathrm{O}$, em quatro ciclos de produção.

resistência; porém, plantas altamente resistentes, ou suscetíveis, praticamente não são afetadas pela nutrição. Como a bananeira 'Prata Anã' apresenta suscetibilidade mediana ao mal do Panamá (Silva et al., 2008b), ela foi altamente responsiva à aplicação de K, ao se considerar que o solo, no presente trabalho, apresentava elevado desbalanço nas disponibilidades de $\mathrm{Ca}, \mathrm{K}$ e $\mathrm{Mg}$.

\section{Conclusões}

1. Para que a máxima eficiência física de produção da bananeira 'Prata Anã' seja atendida, são necessárias doses elevadas de $\mathrm{K}_{2} \mathrm{O}$, como a média de $880 \mathrm{~kg} \mathrm{ha}^{-1}$ obtida no presente trabalho.

2. O valor médio do nível crítico foliar de $\mathrm{K}$, estimado para a bananeira 'Prata Anã' no segundo, no terceiro e no quarto ciclos é de $28,9 \mathrm{~g} \mathrm{~kg}^{-1}$.

3. A incidência do mal do Panamá na bananeira 'Prata Anã', cultivada em solo com disponibilidade desbalanceada de $\mathrm{Ca}, \mathrm{K}$ e $\mathrm{Mg}$, pode ser significativamente reduzida pela adubação potássica.

\section{Agradecimentos}

À Fundação de Amparo à Pesquisa do Estado de Minas Gerais (Fapemig), pela concessão de bolsa.

\section{Referências}

ALVAREZ, C.E.; GARCÍA, V.; ROBLES, J.; DÍAZ, A. Influence des caractérisques du sol sur l'incidence de la Maladie de Panama. Fruits, v.36, p.71-81, 1981.

BANANA: Musa spp.: normas de classificação. São Paulo: Ceagesp, Centro de Qualidade em Horticultura, 2006. 6p. (SECQH. Documentos, 29).

COSTA, E.L. da; COELHO, E.F.; SIMÃO, F.R.; COELHO FILHO, M.A.; OLIVEIRA, P.M. de. Irrigação da bananeira. Informe Agropecuário, v.29, p.38-46, 2008.

DIAS, M.S.C. Doenças da bananeira. Informe Agropecuário, v.29, p.47-58, 2008.

FURTADO, E.L.; BUENO, C.J.; OLIVEIRA, A.L. de; MENTEN, J.O.M.; MALAVOLTA, E. Relações entre ocorrência do Mal-de-Panama em bananeira da cv. Nanicão e nutrientes no solo e nas folhas. Tropical Plant Pathology, v.34, p.211-215, 2009. DOI: 10.1590/S1982-56762009000400002.

LOPES, E.B.; BRITO, C.H. de; ALBUQUERQUE, I.C. de; OLIVEIRA, A.R.R. de. Influência de fatores químicos do solo sobre incidência do mal-do-Panamá na bananeira cv. Pacovan na Paraíba. Revista de Biologia e Ciências da Terra, v.8, p.100-109, 2008.

MALAVOLTA, E.; VITTI, G.C.; OLIVEIRA, S.A. de. Avaliação do estado nutricional das plantas: princípios e aplicações. 2.ed. Piracicaba: Potafos, 1997. 319p.

MARTIN-PRÉVEL, P. Exigências nutricionais da bananicultura. In: SIMPÓSIO BRASILEIRO SOBRE BANANICULTURA, 1.,1984, Jaboticabal. Anais. Jaboticabal: Unesp/FCAV, 1985. p.118-134.

PINTO, J.M.; FARIA, C.M.B. de; SILVA, D.J.; FEITOSA FILHO, J.C. Doses de nitrogênio e potássio aplicadas via fertirrigação em bananeira. Irriga, v.10, p.46-52, 2005.

SANTOS, V.P. dos; FERNANDES, P.D.; MELO, A.S. de; SOBRAL, L.F.; BRITO, M.E.B.; DANTAS, J.D. de M.; BONFIM, L.V. Fertirrigação da bananeira cv. Prata-Anã com N e K em um Argissolo Vermelho-Amarelo. Revista Brasileira de Fruticultura, v.31, p.567-573, 2009. DOI: 10.1590/ S0100-29452009000200035.

SILVA, I.P. da; SILVA, J.T.A. da; PINHO, P.J. de; RODAS, C.L.; CARVALHO, J.G. de. Vegetative development and yield of the banana 'Prata Anã' as a function of magnesium and potassium fertilization. Idesia, v.31, p.83-88, 2013. DOI: $10.4067 /$ S0718-34292013000200012.

SILVA, J.T.A. da; PEREIRA, R.D.; SILVA, I.P.; OLIVEIRA, P.M. de. Produção da bananeira 'Prata Anã' (AAB) em função de diferentes doses e fontes de potássio. Revista Ceres, v.58, p.817-822, 2011. DOI: 10.1590/S0034-737X2011000600020.

SILVA, J.T.A. da; BORGES, A.L.; CARVALHO, J.G.; DAMASCENO, J.E.A. Adubação com potássio e nitrogênio em três ciclos de produção da bananeira cv. Prata-Anã. Revista Brasileira de Fruticultura, v.25, p.152-155, 2003. DOI: 10.1590/ S0100-29452003000100042. 
SILVA, J.T.A. da; CARVALHO, J.G. de. Avaliação nutricional de bananeira 'Prata Anã' (AAB), sob irrigação no semi-árido do norte de Minas Gerais, pelo método DRIS. Ciência e Agrotecnologia, v.29, p.731-739, 2005. DOI: 10.1590/S1413-70542005000400004.

SILVA, J.T.A. da; RODRIGUES, M.G.V. Avaliação nutricional, produção e incidência do mal-do-panamá em bananeira 'Prata-Anã' (AAB) adubada com $\mathrm{K}$, no quarto ciclo. Revista Brasileira de Fruticultura, v.35, p.1170-1177, 2013. DOI: 10.1590/ S0100-29452013000400028.

SILVA, J.T.A. da; SILVA, I.P. da; MOURA NETO, A. de; COSTA, E.L. da. Aplicação de potássio, magnésio e calcário em mudas de bananeira 'Prata-anã' (AAB). Revista Brasileira de Fruticultura, v.30, p.782-786, 2008a. DOI: 10.1590/ S0100-29452008000300037.

SILVA, J.T.A. da; BORGES, A.L.; DIAS, M.S.C.; COSTA, E.L.; PRUDÊNCIO, J.M. Diagnóstico nutricional da bananeira 'Prata-Anã' para o Norte de Minas. Belo Horizonte: Epamig, 2002. 16p. (Epamig. Boletim técnico, 70).
SILVA, J.T.A. da; BORGES, A.L. Solo, nutrição mineral e adubação da bananeira. Informe Agropecuário, v.29, p.25-37, 2008.

SILVA, S. de O. e; PEREIRA, L.V.; RODRIGUES, M.G.V. Variedades. Informe Agropecuário, v.29, p.78-83, 2008 b.

SOUSA, V.F. de; VELOSO, M.E. da C.; VASCONCELOS, L.F.L.; RIBEIRO, V.Q.; SOUZA, V.A.B. de; D’ALBUQUERQUE JUNIOR, B.S. Nitrogênio e potássio via água de irrigação nas características de produção da bananeira 'Grand Naine'. Pesquisa Agropecuária Brasileira, v.39, p.865-869, 2004. DOI: 10.1590/ S0100-204X2004000900005.

VENTURA, J.A.; HINZ, R.H. Controle das doenças da bananeira. In: ZAMBOLIM, L.; VALE, F.X.R. do; MONTEIRO, A.J.A.; COSTA, H. (Ed.). Controle de doenças de plantas fruteiras. Viçosa. Ed. da UFV, 2002. p.839-926.

ZAMBOLIM, L.; VENTURA, J.A. Resistência a doenças induzida pela nutrição mineral das plantas. In: LUZ, W.C.; FERNANDES, J.M.C.; PRESTES, A.M.; PICININI, E.C. (Ed.). Revisão anual de patologia de plantas. Passo Fundo: RAAP, 1993. p.275-317.

Recebido em 17 de novembro de 2014 e aprovado em 29 de julho de 2015 